\title{
Pelvic Ureter
}

National Cancer Institute

\section{Source}

National Cancer Institute. Pelvic Ureter. NCI Thesaurus. Code C160618.

The segment of the ureter that extends from the iliac vessels to the bladder. 